Arteterapia. Papeles de arteterapia y educación para inclusión social ISSN-e 1988-8309

https://dx.doi.org/10.5209/arte.59751

\title{
Estudio de caso: atención arteterapéutica a cuidadora primaria, madre de un hijo con leucemia para favorecer su expresión emocional y afrontamiento ${ }^{1}$
}

\author{
Mónica Reyna-Martínez², Rocío Angélica González-Romo ${ }^{3}$, José Alfredo López ${ }^{4}$
}

Recibido: 1 de abril de 2018/ aceptado: 10 de julio de 2018

Resumen. Se realizó una intervención psicológica con una cuidadora primaria madre de un hijo con leucemia empleando un modelo arteterapéutico. El objetivo general fue favorecer la expresión y el manejo emocional así como el desarrollo de estrategias de afrontamiento adaptativas ante el padecimiento al que se enfrenta. Se aplicó un programa de intervención mediante arteterapia comprendido en cuatro dimensiones: Diagnóstica, sensibilización-psicoeducación, recorrido simbólico y cierre. Los resultados muestran que durante el proceso arteterapéutico se favoreció un proceso creativo que condujo a la reestructuración de vivencias emocionales derivadas del cáncer infantil y al desarrollo de estrategias de afrontamiento funcionales.

Palabras clave: Arteterapia; cáncer infantil; cuidadora primaria; afrontamiento; emociones.

\section{[en] Case study: art therapy care to primary caregiver, mother of a child with leukemia to promote emotional expression and functional coping}

\begin{abstract}
An art therapy intervention was conducted with a mother who was the primary caregiver a child suffering from Leukemia. The general aim was to promote emotional expression and the development of adaptive coping strategies during the child's illness. An art therapy intervention program was applied along four dimensions: diagnosis, sensitization and psycho education, symbolic progress, and closure. Results show that, during art therapy, a creative process was used that led to the resolution of emotional conflicts and the restructuring of emotional conflicts and the development of coping strategies.
\end{abstract}

Keywords: Art therapy; childhood cancer; primary caregiver; coping; emotions.

Sumario. 1. Introducción 2. Método 3. Análisis. 4. Conclusiones.

Cómo citar: Reyna-Martínez, M., González-Romo, R. A., López, J. A. Estudio de caso: atención arteterapéutica a cuidadora primaria, madre de un hijo con leucemia para favorecer su expresión emocional y afrontamiento en Arteterapia. Papeles de arteterapia y educación para inclusión social 14, 2019, 131-146.

$1 \quad$ El presente trabajo formó parte del cuerpo académico Psicología de la salud y Psicoterapia (UASLP-CA-247) y la línea de investigación sobre arte terapia y salud, que derivó en distintos productos de investigación en intervención.

2 Mónica Reyna Martínez: Docente de la Universidad Autónoma de Coahuila.

E-mail: monica.reymar@gmail.com

3 Angélica González Romo: Docente investigadora de la Universidad Autónoma de San Luis Potosí,

E-mail: angelicaglzr@psicologia.uaslp.mx

4 Docente investigador Universidad Autónoma de San Luis Potosí. Facultad de Psicología

E-mail: jalfredolo@psicologia.uaslp.mx 


\section{Introducción}

A nivel mundial, la incidencia anual de cáncer es de 12.45 casos por cada 100000 personas, en el grupo de edad de 0 a 14 años (Instituto Nacional de Estadística y Geografia, 2017). En México, el cáncer en la infancia es la principal causa de muerte por enfermedad entre los niños y niñas de 5 y 14 años, siendo diagnosticados de 5,000 a 6,000 casos nuevos al año, y de los cuales el 65\% se detectan en etapas avanzadas (Organización Panamericana de la Salud, 2017).

Se estima que en países desarrollados, 3 de cada 4 infantes lleguen a una fase de supervivencia 5 años después de iniciar su tratamiento médico (Secretaría de Salud [SS], 2014; SS, 2011). Dicha supervivencia se ha logrado a lo largo de los años, gracias a los adelantos médicos en relación al diagnóstico y tratamiento médico temprano, oportuno y eficaz, llevando al organismo a la remisión de células cancerígenas y logrando con ello una supervivencia prolongada que permite a los pacientes pediátricos gozar de mayores posibilidades de un mejor pronóstico y evolución favorable (Sierrasesúmaga, Antillón, Bernalao, Patiño \& San Julián, 2006). Sin embargo, durante el proceso de la enfermedad tanto el infante con cáncer como su cuidador primario viven experiencias en cada una de las fases propias del padecimiento (diagnóstico, tratamiento médico y convalecencia) que pueden resultar traumáticas por las diversas secuelas físicas y psicosociales, y si no se afrontan de manera funcional.

El comportamiento y estado emocional del cuidador primario a lo largo del proceso de enfermedad tiene una influencia y reflejo en el infante que la padece (Martínez, Martínez \& Corbalán, 2003; Vázquez, 1995), en el contexto del cáncer infantil el objetivo del cuidador es proporcionar recursos para satisfacer las necesidades de subsistencia y adaptación al padecimiento lo que conlleva gasto de tiempo y energía (Robles, 2007). Por otra parte, se ha identificado que el rol de cuidador primario se asigna principalmente a la madre, quien brinda tanto en casa como en el hospital asistencia física y psicosocial, mientras que el padre provee el sustento económico (Velasco \& Sinibaldi, 2000).

\section{Proceso emocional del cuidador primario ante el cáncer infantil}

Los principales efectos emocionales en el cuidador primario durante el proceso de diagnóstico, son la presencia de emociones de ira y de tristeza así como de sentimientos de culpa al sentir que a pesar de sus esfuerzos no realizan los cuidados de manera oportuna y eficaz (Brannon \& Feist, 2001; Martínez et al., 2003; Méndez, Orgilés, López-Roig \& Espada, 2004). Su estado emocional puede traducirse en comportamientos poco adaptativos o saludables, tales como el abandono de rutinas habituales y descuido en su salud (Fornés, 2005). En general estas experiencias son producto de la sobrecarga física y emocional derivada del cuidado del paciente. Durante la fase de convalecencia, hay una preocupación constante por el temor de una recaída, de tal forma que, ante cualquier sintomatología, despierta un estado de angustia y ansiedad, sin embargo, según Grau (2002) simultáneamente mantienen la esperanza de lograr la curación del niño.

\section{Afrontamiento del cáncer infantil}

El afrontamiento, forma parte de un proceso que enfatiza los esfuerzos cognitivos y conductuales para manejar el estrés, y se relaciona con la forma en que los individuos 
resuelven o se sobreponen a las amenazas implicadas en las situaciones vitales estresantes (Folkman, Lazarus, Gruen, \& DeLongis, 1986; Lazarus, 2000; Lazarus, 1993).

El cáncer en un hijo, es una situación que se ajusta a la categoría de condición vital estresante para el paciente y el cuidador primario, generando una serie de respuestas ante el diagnóstico, control y pronóstico de la enfermedad, centrado en la emoción, dirigido a la regulación emocional lo que requiere el uso de recursos cognitivos y conductuales para lograr la adaptación y hacer frente al padecimiento (Pérez, 1999). El afrontamiento tiene dos focos de atención a) centrado en el problema, el cual va encaminado a enfrentar y modificar la situación problemática; y b) centrado en la emoción, dirigido la regulación de emociones para obtener un ajuste psicológico, por lo que el individuo no modifica la situación estresante por considerar que no es posible hacerlo en ese momento (Folkman et al., 1986; Lazarus 1993).

\section{Arteterapia para el afrontamiento del cáncer}

El arte como terapia permite la representación de conflictos, sentimientos y emociones a través de la exteriorización o materialización de la vivencia y subjetividad del paciente por medio de vías creativas y simbólicas utilizando el arte como medio (Loth \& Malchiodi, 2002). El papel del arteterapeuta, es la de propiciar un espacio y un medio de configuración del campo experiencial y su análisis correspondiente, estableciendo un dialogo entre paciente y terapeuta con el objeto creado, que permita comprender su vivencia, su proceso y lo pueda analizar desde distintas perspectivas reevaluando y resignificando experiencias, otorgando un sentido de aprendizaje a lo vivido y por ende un afrontamiento más funcional o adaptativo (Loth, et al., 2002; Rubin, 1998). A su vez el uso de materiales que propicien espacios y encuadres artísticos en los que la persona pueda simbolizar y representar su vida resulta enriquecedor en distintos aspectos, puede mencionarse en primer lugar la oportunidad de representar un momento que ha tenido impacto en el sujeto y que por ende le permite ser una vía no solo de expresión emocional sino de reconfiguración de su realidad, algo que le permite analizar, comprender y reestructurar una experiencia vivida y procesar no solo emociones sino pensamientos, acciones y lo lleve a desarrollar niveles de comprensión más amplios del significado de dicha experiencia para sí mismo y para las personas cercanas a su realidad. En este sentido, las funciones cerebrales desencadenan un proceso creativo, ya que el cerebro es un órgano creador y combinador capaz de reelaborar y crear con elementos de experiencias pasadas nuevas normas y planteamientos. Es así, que mediante la actividad creadora el hombre "hace de él un ser proyectado hacia el futuro, un ser que contribuye a crear y que modifica su presente" (Vigotsky, 2006, p. 13).

\section{Método}

\section{Diseño de la investigación}

Se utilizó la metodología cualitativa de estudio de caso, donde el investigador explora un fenómeno particular para comprender a profundidad las experiencias (Creswell, 2014; Swaborn, 2010), de tal forma que la colecta de información es detallada a tra- 
vés de diversas técnicas en un período sostenido de tiempo (Estaca, 1995; Yin, 2009, 2012; citados en Creswell, 2014). El objetivo es comprender el fenómeno de estudio al centrarse en la indagación de hechos para entender las complejas interrelaciones que se dan en la realidad y generar la construcción del conocimiento. Se eligió el estudio instrumental de caso (Stake, 1995) ya que se reporta una situación única de una cuidadora primaria de forma anecdótica y cualitativa. Los paradigmas interpretativos para el desarrollo fueron el constructivismo y la fenomenología, con el fin de reconstruir experiencias que surgieron a lo largo de la enfermedad mediante una atención de Arteterapia, además de desarrollar aprendizajes y estrategias de afrontamiento para el manejo del cáncer infantil.

\section{Desarrollo del caso}

El criterio de selección del caso refiere a un cuidador primario, sujeto al hecho de tener un hijo con cáncer o en fase de convalecencia (Reyna, González \& López, 2011), dicho cuidador se seleccionó a partir de su participación en un taller de Arteterapia llevado a cabo en una asociación de ayuda a infantes con cáncer en la ciudad de San Luis Potosí, México. Se hizo la selección del caso con base en los criterios de inclusión y la accesibilidad para el trabajo arteterapéutico (González, Reyna \& Cano, 2009).

\section{Criterios de inclusión}

1. Que el paciente tuviera una edad entre los 7 y 10 años. 2. Idioma español en forma escrita y hablada. 3. Diagnóstico de Leucemia Linfoblástica Aguda (L.L.A) 4. Aprobación y firma del consentimiento informado por parte del cuidador primario.

\section{Procedimiento}

Se diseñó un programa de atención para cuidadores primarios, en este caso la madre, tomando en consideración aquellas situaciones críticas acontecidas durante el proceso del cáncer infantil, las cuales son: Diagnóstico, tratamiento médico, hospitalización y efectos colaterales. De esta manera se desarrollaron cuatro etapas 1. Diagnóstica, 2. Sensibilización-Psicoeducación, 3. Recorrido simbólico y 4. Cierre (ver Cuadro 1).

El objetivo al plantear estas etapas fueron: a) reconstruir eventos pasados para identificar emociones, así como sus estilos de afrontamiento frente a situaciones críticas de la enfermedad, b) favorecer la expresión y manejo emocional, c) favorecer la identificación de comportamientos y pensamientos negativos para aprender estrategias de afrontamiento favorables ante el proceso del cáncer y d) integrar el proceso arteterapéutico. Se utilizaron técnicas cognitivas principalmente la imaginación guiada, solución de problemas, imágenes emotivas y la reestructuración cognitiva; mientras que las actividades artísticas estuvieron centradas en el collage, la pintura, el dibujo y modelado.

\section{Procedimiento de las sesiones}

Se trabajó con la cuidadora primaria una vez por semana y cada sesión se distribuyó en las 2 fases planteadas por Dalley (1987) 1. Creación artística: inicio, consigna, creación y expresión artística; y 2. Verbalización: discusión de la obra y cierre de la sesión. 
Cuadro 1. Etapas de la intervención

\begin{tabular}{|c|c|c|}
\hline Etapas & Objetivos & Actividades \\
\hline Diagnóstica & $\begin{array}{l}\text { - Recopilar información sobre } \\
\text { las estrategias de afrontamiento } \\
\text { utilizadas por la cuidadora primaria } \\
\text { ante el cáncer. Recabar información } \\
\text { acerca de la historia de vida del } \\
\text { niño, en las áreas afectiva, social y } \\
\text { cognitiva. }\end{array}$ & $\begin{array}{l}\text { - Entrevista } \\
\text { semiestructurada, } \\
\text { adaptada del } \\
\text { Cuestionario de } \\
\text { Afrontamiento de } \\
\text { Lazarus y Folkman. } \\
\text { - Historia clínica }\end{array}$ \\
\hline $\begin{array}{l}\text { Sensibilización- } \\
\text { Psicoeducación }\end{array}$ & $\begin{array}{l}\text { - Sensibilizarse hacia el proceso } \\
\text { arteterapéutico, conocer sus } \\
\text { principios, establecer el vínculo } \\
\text { arteterapéutico y relación de ayuda. } \\
\text { - Analizar algunos elementos del } \\
\text { padecimiento de cáncer en función } \\
\text { de las necesidades del cuidador } \\
\text { revisando algunos elementos básicos } \\
\text { del cáncer, la leucemia, tratamientos } \\
\text { y efectos colaterales. } \\
\text { - Aplicar algunas técnicas de } \\
\text { respiración y relajación y valorar sus } \\
\text { beneficios. } \\
\text { - Identificar los diferentes tipos de } \\
\text { emociones y sensibilizarse hacia su } \\
\text { expresión y función. }\end{array}$ & $\begin{array}{l}- \text { Encuadre } \\
\text { - Psicoeducación } \\
\text { - Actividades de } \\
\text { arteterapia } \\
\text { - Técnicas de relajación } \\
\text { - Técnicas sobre } \\
\text { identificación de } \\
\text { emociones }\end{array}$ \\
\hline Recorrido simbólico & $\begin{array}{l}\text { - Explorar, identificar y expresar las } \\
\text { emociones evocadas ante: El cáncer } \\
\text { y sus fases, la sensación de saber } \\
\text { que su hijo padece cáncer y su papel } \\
\text { de madre y cuidadora primaria. } \\
\text { - Identificar, analizar y comprender } \\
\text { formas de afrontar el cáncer, } \\
\text { el proceso de la enfermedad y } \\
\text { situaciones asociadas. } \\
\text { - Conocer y comprender sus } \\
\text { necesidades emocionales como } \\
\text { madre y cuidadora } \\
\text { - Conocer nuevas formas de afrontar } \\
\text { sucesos difíciles y el cáncer. }\end{array}$ & $\begin{array}{l}\text { - Actividades de } \\
\text { Arteterapia } \\
\text { - Técnicas de } \\
\text { visualización, } \\
\text { relajación, manejo } \\
\text { de emociones } \\
\text { y situaciones } \\
\text { estresantes. }\end{array}$ \\
\hline Cierre & $\begin{array}{l}\text { - Narrativa y cierre del proceso } \\
\text { arteterapéutico }\end{array}$ & $\begin{array}{l}\text { - Actividades de } \\
\text { Arteterapia } \\
\text { - Psicodrama }\end{array}$ \\
\hline
\end{tabular}




\section{Proceso arteterapéutico}

En este trabajo se presenta a la cuidadora primaria como Elena y al paciente como Carlos (nombres ficticios), mostrando a continuación sus datos sociodemográficos y una descripción de su situación familiar, con el posterior analisis del proceso arteterapéutico.

Cuadro 2. Datos generales.

\begin{tabular}{|l|l|}
\hline \multicolumn{1}{|c|}{ Parentesco del cuidador primario con el paciente } & \multicolumn{1}{c|}{ Madre } \\
\hline Diagnóstico del infante & L.L.A. \\
\hline Edad en que fue diagnosticado & 3 años \\
\hline Tratamiento médico & Quimioterapia \\
\hline Fase de la enfermedad al momento de la investigación & Seguimiento \\
\hline Datos generales de Elena & \multicolumn{2}{|l|}{} \\
\hline Número de sesiones arteterapéuticas & 28 años \\
\hline Edad al inicio del proceso arteterapéutico & San Luis Potosí, México \\
\hline Lugar de nacimiento & Secundaria \\
\hline Escolaridad & Bajo \\
\hline Nivel socioeconómico & Activa-empleada \\
\hline Situación laboral &
\end{tabular}

Situación familiar: Elena refiere que desde la aparición de los primeros síntomas de la enfermedad, se presentaron dificultades en la relación de pareja, por lo cual tanto ella como su hijo cambiaron su lugar de residencia a casa de los abuelos, quienes fungieron como red de apoyo a lo largo del proceso del cáncer. Elena es laboralmente activa y en ocasiones trabaja tiempo extra, por lo que deja a Carlos al cuidado de sus abuelos, lo cual provoca que los límites de autoridad sean difusos respecto a su educación. Elena es proveedora del sustento económico para su hijo, sin embargo, la mayor parte de los cuidados primarios los brindó ella tanto en casa como durante la hospitalización a lo largo del tratamiento médico, las ocasiones en que Elena trabajaba horas extra.

Los resultados obtenidos se categorizaron en las siguientes dimensiones: a) identificación de emociones y formas de afrontamiento utilizadas desde los primeros síntomas hasta la etapa de convalecencia; b) la valoración de su papel de cuidadora primaria y madre; y c) aprendizaje de nuevas formas de afrontamiento frente a la enfermedad y la reevaluación cognitiva del papel de cuidadora primaria.

\section{Identificación de emociones y formas de afrontamiento utilizadas desde los primeros síntomas hasta la etapa de convalecencia}

Elena tuvo la posibilidad de materializar y narrar sus emociones. En la obra "Depredador" (Figura 1) ofreció una panorámica general de la percepción que tenía de la enfermedad, en la que imagina que la leucemia era como un depredador, un animal malo que caminaba y se diseminaba lentamente para hacerle daño al cuerpo de Carlos. El color verde, le recordaba la coloración verdosa que tenía su hijo al inicio de 
los primeros síntomas y la forma de su dibujo denotaba las "células malas que van caminando por el cuerpo". Reconoció que el cáncer, irrumpió de manera brusca en sus vidas e indicó que "un día inesperado mi hijo enfermó y todo cambió, yo todo lo veía gris sin color, nada me parecía y de todo renegaba, (...) descubrí el dolor, la tristeza (...)". Por medio de un mapa de las emociones expuso los sentimientos que experimentó ante el cáncer, principalmente coraje y tristeza, en ese momento ella se preguntaba "¿por qué a mi hijo?”, “¿para qué traje a este niño nomás a sufrir?”. Posteriormente en la misma obra verbalizó que otras emociones provocadas por la enfermedad fueron el temor, la desesperación, la impotencia y la angustia ante el sufrimiento del niño durante la hospitalización y el tratamiento médico.

\section{Afrontamiento ante el diagnóstico del cáncer}

Ante los primeros síntomas de su hijo, utilizó estrategias centradas en el problema, buscó centros de salud en los cuales pudieran darle atención médica, posteriormente al realizarle las pruebas de laboratorio, se confirmó el diagnóstico de L.L.A; reaccionando con negación, mostrándose incrédula ante él y pensando que no era real lo que estaba sucediendo. Posteriormente, tuvo síntomas de depresión y se aisló socialmente, mostrando su visión catastrófica de la enfermedad al relatar lo siguiente: "renegué, no me sentía con ánimos de nada, me sentía como que yo andaba sola en el mundo, a lo mejor yo misma me encerraba en mi mundo, no quería creerlo, me negaba". La afectación emocional que experimentó se pudo apreciar en su obra "Desconsolada" (Fig. 2), dibujo realizado a lápiz que dejó ver los síntomas depresivos que fueron intensificándose durante el proceso de la enfermedad, así mismo, con dicha obra verbalizó que se "(...) sentía como una manzana seca, como un árbol sin frutos y sin vida".

\section{Afrontamiento durante la hospitalización y tratamiento médico}

En su obra "Volver a empezar" la descripción de lo que representó para ella el cáncer y su proceso es "empezar una nueva vida", debido a que el estilo de vida se modificó. Comentó que "se descontrola uno y todo cambia totalmente", porque existe una demanda constante de cuidados especiales que alteran la rutina del cuidador primario. Por otro lado, resume su manejo ante el tratamiento y la hospitalización mencionando que: "el tratamiento me dio miedo, cooperé (...), estuve constantemente preocupada, y con miedo por la enfermedad", sin embargo, a pesar de los temores "me comprometí para que mi hijo saliera adelante, busqué información, me refugié en la religión, tuve confianza y mucho optimismo".

Ella a su vez experimentó una crisis ante la enfermedad originando una desorganización emocional, a partir de lo cual modificó su esquema de vida utilizando la planificación y resolución del problema como estrategias de afrontamiento ante la nueva situación. Esta fase fue especialmente demandante por factores diversos, como los cuidados primarios, su actividad laboral y los cambios emocionales de su hijo durante el tratamiento y las hospitalizaciones. Elena, se sintió en ocasiones incompetente para brindar de forma adecuada los cuidados que requería su hijo, incluso se percibía incapaz de brindar soporte emocional al observar una conducta hostil hacia ella, expresando “(...) ¡no sé hacer nada!, me sentía como una inútil en ese rato!". 


\section{Afrontamiento en la etapa de convalecencia.}

A través de "Aurora" (Fig. 3) manifestó que se sentía tranquila y alegre al recordar la última quimioterapia de su hijo, al respecto dijo que era como "una mujer que se siente a gusto, libre, como si le quitaran la presión". Sin embargo, a pesar del alivio aludido, prevalecieron en ella el temor y la preocupación de una recaída. Dichas emociones la llevaban a preguntarse constantemente “ ¿y si volviera a pasar?”, por lo que mediante su dibujo "Antes y después" indicó que si Carlos llegara morir por el cáncer "lo recordaría como un niño muy feliz que nunca estuvo enfermo". Lo cual denota, una manera de negar el dolor emocional que representaba todo el proceso de enfermedad, ya que su hijo había padecido leucemia desde los 3 años.

\section{Valoración de su papel de cuidadora primaria y madre}

\section{La carga emocional como Cuidadora primaria}

La oportunidad de expresar emociones ante diversas experiencias relacionadas con la enfermedad a través del arte permite comprender su proceso y formas de afrontamiento que se va transformando permitiendo una adaptación al padecimiento.

En un principio, el estado de ánimo la llevaba a ver "todo nublado", experimentando principalmente "coraje [al] ver a otra gente feliz" y negándose a darse el permiso para sentir y expresar alegría en muchas ocasiones. Como cuidadora, el centrarse en la culpa y el remordimiento, en parte, ocasionados por su empleo que no le permitía cubrir todas las demandas que exigía su hijo como paciente, dejándolo algunas veces al cuidado de su abuelo durante la hospitalización.

De esta manera, Elena cayó en el servilismo al hacer todo lo que el niño le solicitaba, así mismo, desarrolló una autopercepción de inutilidad al considerar que no era capaz de cumplir con esas demandas, tal como su hijo deseaba. De este modo el vínculo madre-hijo se tornó dependiente por la experimentación de ansiedad en ambos, llevando a Elena a la sobreprotección y en el caso de Carlos a una victimización.

Por otro lado, la ardua tarea de cuidar y de ser sustento económico, la condujo al aislamiento por falta de búsqueda de redes de apoyo, propiciando con ello una escasa comunicación y ventilación de las emociones, además poca percepción de ayuda tangible y emocional por parte de los demás. Si bien es cierto que sus únicos apoyos fueron sus padres, no les pudo expresar su sentir ya que debía mostrarse con fortaleza debido a que el abuelo insistía en que Carlos "no debía verlos tristes". De ahí, que Elena se inclinara a suprimir las actividades personales de recreación o sociales, centrándose en el cuidado del niño solamente, al parecer como una forma de reducir la culpabilidad por no cuidarlo cuando se encontraba trabajando.

En su obra "Desprotegida" (Fig. 4) dibujó manzanas "frescas y bonitas", que representaban a otras madres de infantes hospitalizados, a los familiares de esos pacientes y al padre de Carlos. Además, había creado otra manzana "triste, marchita, sin color, más débil que las otras", que se encontraba apartada del grupo y que la representaba como una manzana diferente al no sentirse parte del grupo. Esa sensación, la experimentó por creer que no actuaba como las demás madres, ya que debía trabajar y ausentarse del hospital por ese lapso de tiempo. Cuando tenía la oportunidad de asistir a las revisiones de rutina del niño, imaginaba que esas madres pensaban que era una madre desobligada, creyendo que comentaban " $; a y$, que madre 
tan desconsiderada, ella allá [trabajando] y su hijo acá en consulta!”. Con ello, su aflicción se incrementaba y la visión de sí misma era la de una madre diferente, sola y sin el apoyo emocional e instrumental del padre de Carlos, manifestando que de haber contado con su soporte la carga emocional habría sido menos intensa.

\section{Vinculo madre-hijo}

"Aurora" (Fig. 3) puso al descubierto el vínculo estrecho y dependencia que existía entre Elena y Carlos, ya que mostraba dos peces unidos en el extremo inferior representando de esta forma la sobreprotección y la ansiedad de separación suscitados por el cáncer y su proceso. Por esa razón, se observó que el estado anímico de su hijo iba acorde con el de ella, es decir, si el niño percibía tristeza en su madre él se encontraba de esa forma. Como se mencionó anteriormente, a lo largo del proceso arteterapéutico, Elena manifestó el sentimiento de incapacidad en su rol de cuidadora y de madre. En relación al papel de madre, consideraba no tener "derecho sobre el niño", por lo que prefirió dejar en manos de sus padres la educación y toma de decisiones respecto a Carlos. Aunado a lo anterior, se presentó un comportamiento de manipulación, pues cuando Carlos no obtenía lo que deseaba utilizaba frases tales como "mejor me voy al hospital, no me dejan hacer nada, allá no me dicen nada" o "¡ay, ya me voy a morir!; ante lo cual Elena optaba por cubrir los caprichos porque prefería "verlo dando lata, que en una cama de hospital".

La dinámica familiar y las demandas de los cuidados propios de la enfermedad, condujeron a Elena a formarse la idea de ser "una mala madre", por lo que en el proceso arteterapéutico se trabajó en el empoderamiento de su rol de madre, llegando a elaborar e integrar una autoimagen de mujer responsable proveedora de cuidados, cariño y sustento socioeconómico. Lo anterior, dio pie a la toma de control sobre el comportamiento de su hijo, logrando que éste se adaptara a la nueva dinámica familiar y que al mismo tiempo, obtuviera mayor salud emocional.

En la parte final del proceso arteterapéutico surgió de nueva cuenta la sensación de ser "mala madre", esto, por la independencia emocional que se estaba generando y al dejar de percibir al niño como una extensión de ella, visto en "Aurora" (Fig 3). Por lo que en su obra "Sin voluntad" (Fig. 5) introdujo 2 elementos: 1) la mala madre, figura elaborada con gises de colores, y 2) la representación de su hijo, elaborado con papel de china color café. Con tal representación, expresó que la madre y su hijo estaban unidos anteriormente, porque "un hijo es parte de uno", pero el hijo se estaba separando de la madre y solamente los unía un vínculo, en este caso la extensión realizada con color café, que mantenía unidos a los dos elementos de la obra. La preocupación de tal separación llevaba a la madre a sentirse una "mala madre", al considerar que al estar de acuerdo con la separación, significaba que ésta "no quería apoyar a su hijo", que no lo amaba y que le hacía falta voluntad para mantenerlo junto a ella.

\section{Aprendizaje de nuevas formas de afrontamiento frente al proceso de enfermedad: Resignificación del papel de cuidadora primaria}

Durante el proceso arteterapéutico, la cuidadora primaria logró expresar todas aquellas emociones que emergieron durante la enfermedad de su hijo, consiguiendo darle otro sentido al cáncer en cada una de sus fases. En primera instancia, la psicoeduca- 
ción le permitió asimilar y comprender que ella no era culpable, ni la causante del desarrollo de la leucemia de su hijo. Aunado a esto se observó que, al reevaluar sus experiencias, con la guía de un acompañamiento terapéutico le permitió resolucionar visiones fatalistas de manera simbólica ante el análisis de sus producciones, dando paso a comentarios más adaptativos, por ejemplo: "yo era como un árbol seco, y ahora estoy dando frutos y Carlos va creciendo".

Con la construcción de "El árbol" (Fig. 6) mencionó que tuvo diversos aprendizajes que se presentan en el cuadro 3.

Cuadro 3. Aprendizajes percibidos por Elena a lo largo del proceso arteterapéutico

\begin{tabular}{|l|ll|}
\hline \multirow{1}{*}{ Logros } & - & Enfrenté mis miedos, a la enfermedad o a una recaída. \\
- & $\begin{array}{l}\text { Aprendí a ejercer mi autoridad, le pongo límites al niño, noto que ya } \\
\text { me obedece, me respeta. }\end{array}$ \\
- & $\begin{array}{l}\text { Expreso mis sentimientos al niño, además de poder expresar mis } \\
\text { emociones y experiencias en terapia. }\end{array}$ \\
- & $\begin{array}{l}\text { Resolví culpas, me siento más tranquila y calmada. } \\
-\end{array}$ & $\begin{array}{l}\text { Comprendí los miedos de Carlos, he pensado más en la manera de } \\
\text { solucionar las cosas. }\end{array}$ \\
- & $\begin{array}{l}\text { Aclaré mis emociones, antes estaba frustrada por la enfermedad, me } \\
\text { sentía triste y encerrada ya que no había superado la situación difícil. }\end{array}$ \\
- & $\begin{array}{l}\text { Ahora percibo la enfermedad como una etapa pasada. } \\
-\end{array}$ & $\begin{array}{l}\text { Aprendí a decir lo que pienso y a darme cuenta de que el hecho de que } \\
\text { trabajara no significaba que no cuidara a Carlos. }\end{array}$ \\
\hline Fortalezas & $\begin{array}{l}\text { Valentía, para platicar con mis papás y hacerme responsable del niño. } \\
-\end{array}$ & $\begin{array}{l}\text { Confianza en mí misma, descubrí que soy capaz tomar el control de } \\
\text { mí misma. }\end{array}$ \\
- & $\begin{array}{l}\text { Superar la leucemia. } \\
\text { Valor para actuar como la madre de Carlos. }\end{array}$ \\
- & $\begin{array}{l}\text { Darme cuenta de la importancia de los cuidados. } \\
\text { Ya no siento miedo por el cáncer, el dolor ha quedado atrás. }\end{array}$ \\
\hline
\end{tabular}

También se utilizaron ejercicios de reestructuración cognitiva, con el fin de que pusiera a prueba las creencias negativas que desencadenaron su autoimagen de mala cuidadora y mala madre, como se muestra en el ejemplo de la tabla 1.

De esta forma, pudo terminar su proceso arteterapéutico con una autoimagen de una madre ejemplar para su hijo, capaz de cuidarlo y conducirlo en la vida, que si bien actuó erróneamente en algunas ocasiones, se dio cuenta de que su espíritu de lucha frente a la enfermedad la hacían una mujer valiosa. Su desarrollo personal se manifestó en el cambio de creencias acerca de sí misma y de su rol como cuidadora; en la reevaluación positiva de la enfermedad; en la búsqueda de lazos sociales para expresar sus sentimientos y compartir experiencias que no solo implicaban a la enfermedad, y finalmente en la expresión del amor hacia su hijo. 
Tabla 1. Ejercicio de reestructuración cognitiva

\begin{tabular}{|c|c|}
\hline \multicolumn{2}{|c|}{$\begin{array}{l}\text { Situación conflictiva } \\
\text { No lo podía llevar a las consultas, debido a que yo estaba trabajando por las mañanas }\end{array}$} \\
\hline $\begin{array}{l}\text { Emociones que } \\
\text { emergieron e } \\
\text { Intensidad } \\
(0 \text { al 10) }\end{array}$ & $\begin{array}{l}\text { Coraje (3): porque no había quien me supliera para poder ir con él. Lo } \\
\text { manifestaba desquitándome con todos, mi mamá me decía que me comportaba } \\
\text { como si los demás tuvieran la culpa. Me sentía irritable. } \\
\text { Angustia (5): por temor a que pasara algo grave, que la Doctora dijera algo } \\
\text { importante y que mi papá no supiera explicarme. Esta angustia la manifestaba } \\
\text { llamando por teléfono constantemente a mi mamá para tener noticias. } \\
\text { Tristeza (8): porque no lo podía acompañar. Me distraía, como si no estuviera } \\
\text { en el trabajo. }\end{array}$ \\
\hline $\begin{array}{l}\text { Pensamiento } \\
\text { automáticos }\end{array}$ & $\begin{array}{l}\text { - } \quad \text { Mentir en el trabajo para no ir y acompañar a Carlos a las consultas. } \\
\text { - } \quad \text { Cuando lo acompañaba pensaba que las otras mamás decían ¿será la } \\
\text { mamá o qué? } \\
\text { - } \quad \text { No estaba cumpliendo al } 100 \text { y no sabía cuidarlo. } \\
\text { - } \quad \text { Soy torpe cuando lo cuido. [Al respecto recordó que en una ocasión la Dra. le } \\
\text { pidió que sostuviera a Carlos para aplicar la punción lumbar, al momento de } \\
\text { ver la aguja se asustó y movió al niño de su posición, por lo que ésta le pidió } \\
\text { que abandonara la sala]. } \\
\text { - No tenía la fortaleza necesaria para darle un apoyo, ¿por qué soy tan } \\
\text { cobarde que no puedo? }\end{array}$ \\
\hline $\begin{array}{l}\text { Evidencias a } \\
\text { favor: validación } \\
\text { de pensamientos } \\
\text { automáticos }\end{array}$ & $\begin{array}{l}\text { - Si cumplía pero no al } 100, \text { le daba las medicinas, seguía las indicaciones, } \\
\text { pero me hubiera gustado estar presente en todas las consultas médicas } \\
\text { para preguntar todas las dudas. } \\
\text { - } \quad \text { Cuando la Dra. me sacó de la sala al asustarme por la punción lumbar } \\
\text { - Soy torpe } \\
\text { - No sabía cuidarlo porque no hacía las cosas como yo pensaba que } \\
\text { deberían ser. }\end{array}$ \\
\hline $\begin{array}{l}\text { Evidencias en } \\
\text { contra }\end{array}$ & $\begin{array}{l}\text { - } \begin{array}{l}\text { Iba al Hospital a buscar a la Dra. en otros horarios para preguntar y } \\
\text { aclarar dudas. }\end{array} \\
\text { - } \quad \text { Cuando vi el tamaño de la aguja me asusté, pero si me hubiera explicado } \\
\text { antes me hubiera hecho la fuerte para no entorpecer el trabajo de la Dra. } \\
\text { - } \quad \text { No hubiera cambiado nada si hubiera asistido a consulta, porque la Dra. } \\
\text { nos decía palabras que no comprendía, además que eran revisiones de } \\
\text { rutina. } \\
\text { - Lo acompané en las tardes durante la hospitalización, lo cuidé en las } \\
\text { noches, le daba de comer en la madrugada, lo atendí cuando tenía } \\
\text { calentura, bañarlo, darle los medicamentos. } \\
\text { - Sí cumplí al 100, porque siempre estuve al pendiente de su evolución, } \\
\text { busqué información en internet y libros sobre el cáncer. } \\
\text { - Si sabía cuidarlo, solo que no lo hacía como él exigía, ni como la Dra. } \\
\text { esperaba que lo hiciera cuando sucedió lo de la punción. } \\
\text { - Trabajé porque era necesario que Carlos tuviera un seguro médico, para } \\
\text { brindarle mayor calidad de vida. }\end{array}$ \\
\hline $\begin{array}{l}\text { Reevaluación de } \\
\text { emociones }\end{array}$ & $\begin{array}{l}\text { Tristeza (2): me dio gusto saber que si cumplí con mi papel de madre y } \\
\text { cuidadora, ya que anteriormente no me daba cuenta. } \\
\text { Angustia (1) ya no me siento torpe ni poco capaz } \\
\text { Coraje (0): me di cuenta que desempeñé un buen papel y que sí fue capaz de } \\
\text { cuidarlo }\end{array}$ \\
\hline
\end{tabular}




\section{Análisis}

Se realizó una intervención utilizando el Arteterapia en una cuidadora primaria, identificándose las cuatro fases del proceso creativo, que se explican a continuación tomando como referencia a los autores González (2004) \& Boden (1994).

Preparación: En esta etapa la persona se encuentra altamente motivada y posee una actitud abierta, flexible y fluida hacia la búsqueda de alternativas de solución a un problema planteado de forma consciente, usando y adaptando métodos conocidos y explorando alternativas aún no conocidas; de igual forma se va procesando la información en la mente de manera abstracta. Específicamente en este estudio, la fase de preparación corresponde a las etapas diagnóstica y psicoeducativa, representando una herramienta cognitiva que permitió a la cuidadora identificar las emociones y aprender nuevos conceptos relacionados con el cáncer, contribuyendo al procesamiento de información y acomodamiento de los conocimientos adquiridos.

Incubación: En esta etapa se desencadenan procesos propios del pensamiento que pueden durar minutos o meses, lapso en el que por debajo del nivel de consciencia se gesta una idea creativa o soluciones de problemas. Esta etapa en nuestro sujeto de estudio corresponde a la mayor parte del Recorrido Simbólico, manifestando a través de las obras creadas las emociones y los sentimientos más dolorosos que emergieron durante la enfermedad de su hijo. La cuidadora fue capaz de identificar sus formas de afrontamiento gracias a la preparación que tuvo previamente. Su discurso fue reiterativo y la mayor parte de las creaciones artísticas se tornaron estereotipadas, al respecto se observó que dibujó puentes en diversas ocasiones.

Por otra parte, además de manifestar resistencias emocionales a través de la negación de la existencia de conflictos, se observaron inasistencias y cancelación de sesiones, por lo que parecía que abandonaría su proceso arteterapéutico. Lo anterior se puede explicar porque en la etapa de incubación del proceso creativo, es común que las personas se enfrenten a la ambigüedad y a la frustración, manifestados a través de bloqueos mentales o resistencias perceptuales, cognitivas y/o afectivas, que llevan muchas veces a la claudicación. Se tratan de defensas ante la amenaza de un nuevo camino, que pondrían en peligro pensamientos y sentimientos que les resultan familiares a las personas. Sin embargo, cuando se toleran, se obtienen nuevas estructuras mentales.

Iluminación: En esta etapa ocurre la experimentación de una gran claridad en la idea a desarrollar, derivado de un trabajo previo, permite tomar conciencia de la idea de una forma más clara, flexible y fluida, implicando la corazonada que tiene la persona al dar con la respuesta perfecta y justa a lo que está trabajando. En la cuidadora, la etapa de incubación permitió el procesamiento de la información, por lo que, de utilizar un discurso repetitivo relacionado con la reconfiguración de la vivencia emocional derivada del cáncer, pasó a darse cuenta que se sentía profundamente culpable, por creer que el cuidado brindado al niño no había sido suficiente. Asimismo, pudo expresar mediante su obra "El árbol", que se sentía "mal y triste" porque creía haber superado el dolor y el rencor que emergieron por la falta de apoyo emocional y económico de las personas más cercanas. Lo anterior, abrió paso a una iluminación que puso en evidencia la problemática y los caminos para resolverla, por lo cual en la siguiente etapa se trabajaron aquellas concepciones negativas acerca de su papel de cuidadora y madre.

Verificación de problemas: En esta etapa, se da la resolución deliberada del problema, elaborando la idea de tal forma que sea comprensible para él mismo o los demás para comunicarla. Es común que la persona vuelva a experimentar las etapas 
anteriores en distintos momentos, debido a que se prueban maneras para resolver un problema previamente procesado, después se revisa, corrige y se vuelve a intentar, hasta verificar que la idea o solución para el problema es la más efectiva y adecuada. Para la cuidadora primaria, lo anterior tuvo lugar aproximadamente en un lapso de un mes y medio, iniciando con la obra "Desprotegida" con la que materializó su soledad y sentimientos de desprotección. Dicha obra, la condujo de nueva cuenta a la etapa de incubación para dar solución a la falta de apoyo que percibía de su entorno. Posteriormente, con la creación "Sin voluntad" se llevó a cabo la iluminación que proyectaba una imagen devaluada de cuidadora y madre, por lo que finalmente llegó a la reevaluación positiva de sí misma, a través de ejercicios de reestructuración cognitiva. Al obtener recursos cognitivos y emocionales desde la etapa de preparación, a la cuidadora le fue posible resignificarse, por lo que el vínculo madre-hijo se modificó pasando de un apego ansioso a uno seguro. Conjuntamente se observó un empoderamiento de sus roles frente al proceso del cáncer infantil, provocando que el menor adquiriera a su vez aprendizajes acerca de los límites proporcionados por ella y la aceptación de la reorganización familiar dejando a un lado la ansiedad y el papel de víctima por la enfermedad. La cuidadora, al aprender formas de afrontamiento adaptativas frente a los problemas asociados con el cáncer pudo elaborar sus sentimientos de culpabilidad y dar paso a la expresión de sus emociones contribuyendo de esta manera al alivio de la sobrecarga emocional que está implicada en esta ardua tarea.

\section{Conclusiones}

En resumen, podemos observar que en este proceso arteterapéutico, se desarrolló un proceso creativo que hizo posible el aprendizaje de nuevas estrategias de afrontamiento frente al cáncer, tales como el desarrollo personal, la búsqueda de apoyo social, la ventilación de experiencias traumáticas y emociones dolorosas, así como la reevaluación positiva tanto del padecimiento como del autoconcepto de madre y cuidadora. Es importante señalar que la metodología del Arteterapia, ofrece posibilidades para la producción de obras que contengan fragmentos de experiencias vividas frente a la enfermedad y con ello se pueda construir posibilidades para restaurar dichos eventos, que finalmente llevan a la generación de nuevos planteamientos para el cambio o manejo de situaciones difíciles. En este proceso creativo, se promovió el dinamismo y la flexibilidad mental, por medio de un arduo trabajo que llevó al descubrimiento de posibilidades para lograr un ajuste y bienestar psicológico a pesar de las resistencias, así como la ansiedad por abandonar formas de actuación o estructuras mentales ya conocidas. Al ser la creatividad un proceso no lineal, la cuidadora primaria pudo retornar a etapas de preparación e incubación para no claudicar, para seguir reelaborando y transformándose; por esta razón aprendió a tolerar la ambigüedad mientras que seguía reacomodando en su interior tanto imágenes, percepciones, afectos y sentimientos, hasta llegar a la construcción de nuevos significados.

\section{Aportaciones del estudio}

El Arteterapia, es un recurso valioso para el tratamiento psicológico de las personas que se encuentran inmersas en una dinámica de enfermedad como el cáncer infantil. La me- 
todología de esta terapia provee de herramientas cognitivas como la creatividad, contribuyendo de forma favorable al manejo de emociones y al aprendizaje de estrategias de afrontamiento frente al padecimiento y eventos asociados. Por esa razón, a nivel teórico el presente trabajo puede ayudar a la integración de los conceptos del proceso creativo para explicar de qué manera se generan los cambios psicológicos en las personas tratadas bajo el Arteterapia. Por otro lado, este estudio nos ofrece una panorámica general de las situaciones estresantes que vive una cuidadora primaria ante las fases del cáncer infantil, por lo que al observar resultados favorables se valora el Arteterapia para el tratamiento emocional dentro del contexto de la Psicología de la Salud y la Psicooncología.

Lo anterior, se recomienda debido a que los cuidadores desde el inicio del cáncer se enfrentan al estrés y formas de actuación disfuncionales, que se generan por la demanda de cuidado, que como consecuencia conlleva un desgaste físico y emocional que repercute de manera negativa en su calidad de vida (Caqueo-Urízar, SegoviaLagos, Urrutia-Urrutia, Miranda \& Navarro, 2013). Además, se ha encontrado que por la complejidad del proceso del cáncer, los cuidadores se ven afectados de forma negativa a nivel personal y familiar conforme el paciente experimenta el curso de la enfermedad, igualmente, se ha identificado que pueden presentar sintomatología de estrés postraumático en mayor medida que sus propios hijos enfermos (LópezHuerta, Álvarez-Bermúdez \& González-Romo, 2012; Islas, Ramos, Aguilar \& García, 2006). Por esa razón, esta atención debe enfocarse en la expresión emocional y la psicoeducación del padecimiento, facilitando la exploración de creencias, dudas y temores respecto al cáncer, de tal forma que tanto ellos, el niño y su familia, aprendan a reorganizar roles perdidos, afrontar activamente el padecimiento, manejar la ansiedad y a aceptar circunstancias difíciles ocurridas como consecuencia de la evolución y el tratamiento médico (González, López \& Estrada, 2014).

De esta manera, se concluye que a nivel práctico la presente investigación puede ser un aliciente para que los profesionales dedicados al campo de la salud se interesen más en la implementación de intervenciones psicológicas y arteterpéuticas para paliar el sufrimiento y la carga emocional, con lo cual se pueda observar una mejoría no solo a nivel personal en el cuidador, sino también a nivel externo, favoreciendo en gran medida la salud psicológica del niño y de la familia, viéndose manifestada en un mejoramiento de la comunicación, del vínculo afectivo, la adherencia al tratamiento, entre otros.

\section{Referencias}

Boden, M.A. (1994). La mente creativa: mitos y mecanismos. Buenos Aires: Gedisa Brannon, L. \& Feist, J. (2001). Psicología de la Salud. España: Thomson Editores.

Caqueo-Urízar, A., Segovia-Lagos, P., Urrutia-Urrutia, U., Miranda, C. \& Navarro, (2013). Impacto de la relación de ayuda de cuidadores primarios en la calidad de vida de pacientes con cáncer avanzado. Psicooncología, 10(1), 95-108. doi: 10.5209/rev_PSIC.2013.v10.41950

Creswell, J. (2014). Research design qualitative, quantitative and mixed methods approaches. London: SAGE

Dalley, T. (1987). El arte como terapia. Barcelona: Herder

Folkman, S., Lazarus, R.S., Gruen, R.J., \& DeLongis, A. (1986). Appraisal, coping, health status, and psychology symptoms. Journal of Personality and Social Psychology, 50(3), 571-579. doi: 10.1037/0022-3514.50.3.571 
Fornés, J. (2005). Enfermería de la salud mental y psiquiátrica: planes de cuidados. Buenos Aires: Madrid: Médica Panamericana.

González, R.A. (2004). Creatividad en la investigación: persona, proceso, producto y contexto desde la experiencia del investigador. Xalapa, Universidad Veracruzana.

González, R.A, López, J., Estrada, B. (2014). Abordaje psicoeducativo del niño con cáncer y de su familia. En Pérez, I., Lamoglia, M., Godall, M. Pediatría en atención primaria de salud. Un abordaje multidisciplinar. Madrid: Editorial Médica Panamericana, pp. 215-221.

González, R.A., Reyna, M. \& Cano, C.C. (2009). “Los colores que hay en mí: una experiencia de arteterapia en pacientes oncológicos infantiles y cuidadores primarios". En Revista de Enseñanza e Investigación en Psicología, 14(1), 77-94. Recuperado de http://www. redalyc.org/articulo.oa? $\mathrm{id}=29214106$

Grau, C. (2002). Impacto psicosocial del cáncer infantil en la familia. Educación, desarrollo y diversidad, 5(2), 67-87. Recuperado de http://roderic.uv.es/bitstream/ handle/10550/41639/004320.pdf?sequence=1\&isAllowed=y

Instituto Nacional de Estadística y Geografía. (2017). Estadísticas a propósito del día mundial contra el cáncer (4 de febrero). Datos nacionales. Recuperado de http://www.inegi.org. $\mathrm{mx} /$ saladeprensa/aproposito/2017/cancer2017_Nal.pdf

Islas, N.L., Ramos, B., Aguilar, M.G. \& García, M.L. (2006) Perfil psicosocial del cuidador primario informal del paciente EPOC. Artemisa, 19(4), 266-271. Recuperado de http:// www.scielo.org.mx/pdf/iner/v19n4/v19n4a6.pdf

Lazarus, R. (2000). Estrés y emoción: manejo e implicaciones en nuestra salud. España: Desclée de Brouwer.

Lazarus, R. (1993). Coping Theory and Research: Past, Present and Future. Psychosomatic Medicine, 55, 234-247. doi: 10.1097/00006842-199305000-00002

López-Huerta, J.A, Álvarez-Bermúdez, J. \& González-Romo, R.A. (2012). La experiencia psicosocial de padres de hijos con leucemia en un hospital público de la ciudad de San Luis Potosí. Psicooncología, 9(1), 137-150. doi: 10.5209/rev_PSIC.2012.v9.n1.39143

Loth, A. \& Malchiodi, C. A. (2002). Cognitive-Behaviorial Approaches. En Handbook of art therapy. E.U.A: Guilford Press, pp. 72-81.

Martínez, F., Martínez, J. \& Corbalán, F. (2003). Cáncer infantil/adolescente: una aproximación psicológica. En J.M. Ortigosa, M.J. Quiles \& F.J. Méndez, Manual de psicología de la salud con niños, adolescentes y familia. Madrid: Pirámide, pp.197-229.

Méndez, X., Orgilés, M., López-Roig, S. \& Espada, J.P. (2004). Preparación a la hospitalización (I): afrontamiento del estrés. Psicología Conductual, 4(2), 193-209.

Organización Panamericana de la Salud. (2017). Cáncer Infantil en México: situación actual y retos. Washington, D.C. Recuperado de http://www.paho.org/hq/index.php?option=com docman\&task=doc_download\&gid=38141\&Itemid=270\&lang=en.

Pérez, F.J. (1999). Respuestas emocionales, enfermedad crónica y familia. En E. FernándezAbascal \& F. Palmero. Emociones y salud. Barcelona: Ariel, pp.301-324.

Reyna, M., González, R.A. \& López, J.A. (2011). Un mapa para llegar a la vida: estudio de caso de un niño con leucemia mediante arteterapia. Arteterapia. Papeles de arteterapia y educación artística para la inclusión social, 6, 51-167. doi: 10.5209/rev_ARTE.2011.v6.37090

Robles, L. (2007). La invisibilidad del cuidado de los enfermos crónicos: Un estudio cualitativo en el barrio de Oblatos. Guadalajara: Editorial Universitaria.

Rubin, J.A. (1998). Art therapy: an introduction. E.U.A.: Psychology Press.

Secretaría de Salud. (2014). Cáncer en la infancia y la adolescencia. México: Secretaría de Salud del Estado de Veracruz. Recuperado de http://www.ssch.gob.mx/rendicionCuentas/ archivos/Cancer\%20en\%201a\%20Infancia $\% 20 y \% 201 \mathrm{a} \% 20$ Adolescencia.pdf 
Secretaría de Salud. (2011). Perfil Epidemiológico del Cáncer en Niños y Adolescentes. México: Secretaría de Salud. Recuperado de https://epidemiologiatlax.files.wordpress. com/2012/10/p_epi_del_cancer_en_nic3b1osyadolescentes_mexico.pdf

Sierrasesúmaga, L., Antillón Klussmann, F., Bernalao, E., Patiño, A., \& San Julián, M. (2006) Tratado de Oncología Pediátrica. Madrid: Pearson.

Stake, R. (1995). The art of case study research. United States of America: SAGE.

Swanborn, P. (2010). Case Study research. What, why and how. India: SAGE.

Vázquez, A. (1995). Comportamiento del niño hospitalizado. En R. Martínez y Martínez, La salud del niño y del adolescente. México: Masson, pp.1256-1261.

Velasco, M.L. \& Sinibaldi, J.F.J. (2000). Manejo del enfermo crónico y su familia: sistemas, historias y creencias. México: Manual Moderno.

Vigotsky, L. (2006). La imaginación y el arte en la infancia. México: Ediciones Coyoacán. 